\title{
Ultrastructural and Functional Differentiation of the Malpighian Tubules of the Lantern Bug, Pyrops candelaria Linn. (Homoptera: Fulgoridae)
}

\author{
W. W. K. Cheung \\ Department of Biology, The Chinese University of Hong Kong, Shatin, N. T., \\ Hong Kong
}

Received July 31, 1979

Typical homopteran insects like cicadas and cercopids have their malpighian tubules enter into formation of the so-called cicadoid filter chamber complex, and are for 'priming' filtration of excess water to the hindgut (Cheung and Marshall 1973a, 1973b, Marshall and Cheung 1974). In addition to the latter function, malpighian tubules of cercopids are specialised for secreting spittle, probably a mucopolysaccharide (Marshall 1966) and machaerotid malpighian tubules produce fibrils for tube building (Marshall 1965, 1968, Marshall and Cheung 1973).

Fulgorids have their alimentary canal and malpighian tubules differ from those of cicadoid insects (Goodchild 1963, 1966). Like the cicadoid insects they are also sap-suckers; but their feeding site is cambium and parenchymatous cortex rather than xylem vessels (Marshall and Cheung 1975).

The chemical composition or water content of cambium and parenchymatous cortex is drastically different from that of xylem sap (Steward and Sutcliffe 1959). Subsequently, the problem of ionic balance in fulgorids is expected to be different from that in cicadoid insects.

The lantern bug, Pyrops candelaria (also known as Fulgora candelaria) has a simple coiled gut (Kershaw 1910). Like many other fulgorids, it is enclosed by an intestinal sheath. Goodchild (1966) has postulated that this intestinal sheath serves as an 'osmotic barrier' to safeguard the body fluid from dilution by ingested plant sap. However, this suggestion has not so far been verified by physiological experiment, nor the ultrastructure of this sheath been investigated.

Marshall and Cheung (1970) had made an ultrastructural study of the surface coat of the midgut, and the fine structure of the rectum was reported by Cheung (1979). The rectum was found to have an ultrastructure in consistent to that of water conservation.

The malpighian tubules of Pyrops have not been previously investigated. They are, undoubtedly, related to excretion and hydromineral regulation of the insect. A study of the fine structure and cytochemistry of the malpighian tubules may throw some light on these functions.

Materials and methods

Adults of Pyrops (Fulgora) candelaria L. were collected from Lychee and Longan 
groves in the New Territories of Hong Kong Colony. Dissections were made in $0.2 \mathrm{M}$ phosphate buffer, $\mathrm{pH} \mathrm{7.2,} \mathrm{and} \mathrm{pieces} \mathrm{of} \mathrm{malpighian} \mathrm{tubules} \mathrm{were} \mathrm{fixed} \mathrm{in}$ $2.5 \%$ glutaraldehyde in $0.1 \mathrm{M}$ phosphate buffer, $\mathrm{pH} 7.2$, for $1 \mathrm{hr}$., postfixed in $1.0 \%$ osmium tetroxide in phosphate buffer and embedded in araldite after dehydration with acetone series. Sections were cut with a Porter-Blum ultrotome II or Reichart ultrotome and were stained with uranyl nitrate or acetate and lead citrate. Sections were observed in a Hitachi HS-8 or Zeiss EM 9S-2 electron microscope. Thick sections for light microscopy were also cut with a Porter-Blum ultrotome II or Reichart ultrotome and were stained in $1 \%$ toluidine blue in $1 \%$ borax.

For histological observations material was fixed in formol saline, embedded in paraffin wax $\left(56^{\circ} \mathrm{C}\right)$ and sectioned at $6 \mu$. Sections were routinely stained with haematoxylin and eosin.

For cytochemical studies, tissues were fixed in the appropriate fixatives and subjected to the following tests according to Pearse (1968): Alcian blue (pH 3.0) and toluidine blue for mucoprotein, acid solochrome cyanine for proteins, PAS for glycogen (with diastase digestion as control), Sudan black B for lipids, calcium, magnesium, phosphate and uric acid tests.

Tests for enzymes which are associated with transport and metabolism include alkaline phosphatase (Fedricsson 1952), ATPase (Wachstein and Meisel 1957), glucose-6-phosphatase (Wachstein and Meisel 1956), acid phosphatase (Barka and Anderson 1963), $\beta$-glucuronidase (Seligman et al. 1954), cytochrome oxidase (Culling 1963) and succinic dehydrogenase (Barka and Anderson 1963).

\section{Observations}

The general organisation of Pyrops gut is shown diagrammatically in Fig. 1. There are four malpighian tubules arising independently from the pyloric junction of the midgut and hindgut. A Pyrops malpighian tubule can be conveniently divided into 2 regions based on external morphology: proximal tubule and distal tubule. The distal tubule is yellowish brown, "globular" in surface appearance, and is about three-quarter length of the whole tubule. These 2 regions differ in histology, ultrastructure and cytochemical properties.

\section{Distal tubule}

In the light microscope, transverse sections of the distal tubule show an epithelium one-cell thick with 2-3 cells surrounding the lumen. A wide brush border, approximately $4 \mu$ tall, is seen, and the lumen is filled with granular substance which could be excretory products (Fig. 2). There are numerous birefringent granules in the ground cytoplasm. A centrally placed nucleus is vaguely seen in each cell (Fig, 2).

\section{Ultrastructure}

In the electron microscope the microvilli are $4-5 \mu$ in length (Figs. 4, 6). The ground cytoplasm has little endoplasmic reticulum but abundant osmiophilic granules or spherites (Fig. 4). 
Spherites of different osmiophilic properties can be seen (Figs. 7, 8, 9, 10, 11). grade from dark granular deposits in the mitochondria (Fig. 8) to swollen "mineralised' mitochondria (Fig. 8,9) with mitochondrial membranes arranged in concentric whorls (Figs. 10,11). Old spherites are fully packed with minerals (confirmed by cytochemical tests) and the contents can drop off during sectioning, as shown in Figs. 9 and 11.

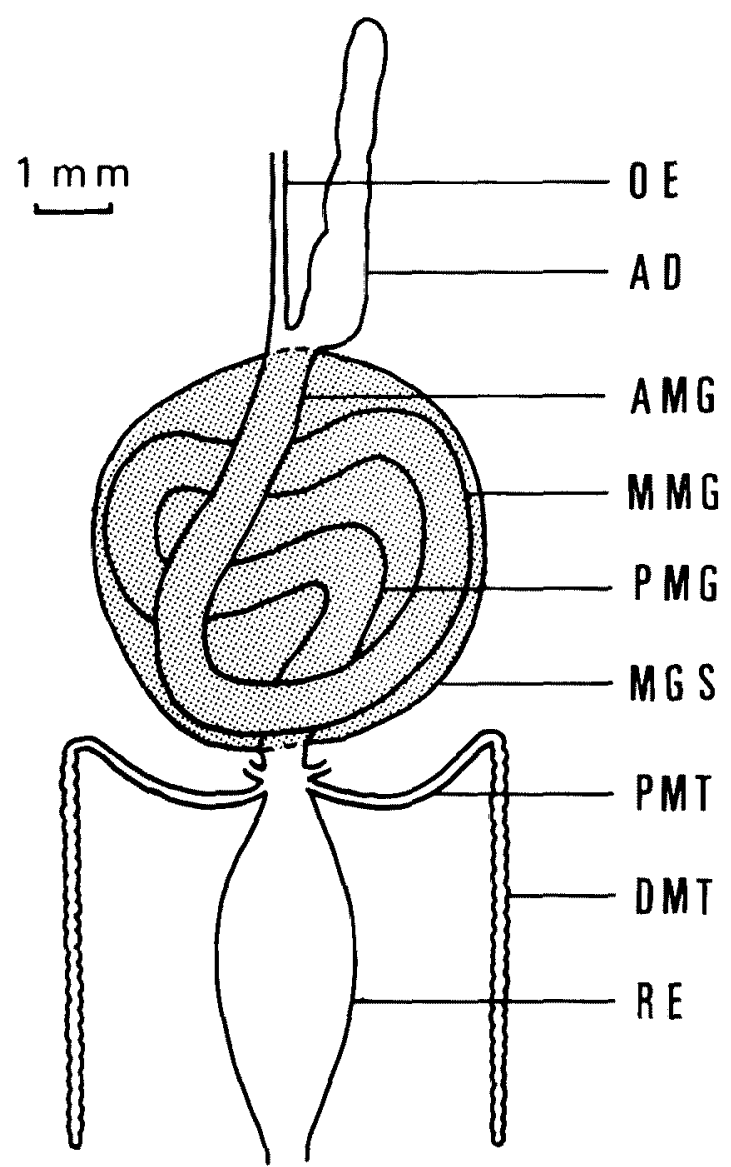

Fig. 1. Diagrammatic representation of the gut of Pyrops. AD, anterior diverticulum; AMG, anterior midgut; DMT, distal malpighian tubule; MGS, midgut sheath; MMG, mid-midgut; $O E$, oesophagus; PMG, posterior midgut; PMT, proximal malpighian tubule; RE, rectum

The apical cytoplasm has numerous mitochondria and some dense vesicles (Fig. 6).

The basement membrane is $0.5 \mu$ thick (Fig. 4) with deep infoldings extending one-quarter distance to the apical surface. Abundant mitochondria are associated with these infoldings (Fig. 4).

\section{Cytochemistry}

The distal tubule cells yield strongly positive results with tests for ATPase, glucose-6-phosphatase, cytochrome oxidase, and succinic dehydrogenase. The re- 
action products are mainly localised in the basal region of the cells. Weakly positive reactions are obtained with tests for alkaline phosphatase and $\beta$-glucuronidase. Tests for calcium, magnesium, and phosphates indicate positive results. Test for uric acid, however, indicates a negative result.

Table 1 summarises the cytochemical properties of the distal tubule cells.

\section{Proximal tubule}

In the light microscope, transverse sections of the proximal tubule show an epithelium one-cell thick with 4-5 cells surrounding the lumen. Each cell has a prominent nucleus (Fig. 3). The tubule lumen is narrow and appears to be filled with secretory products (Fig. 3).

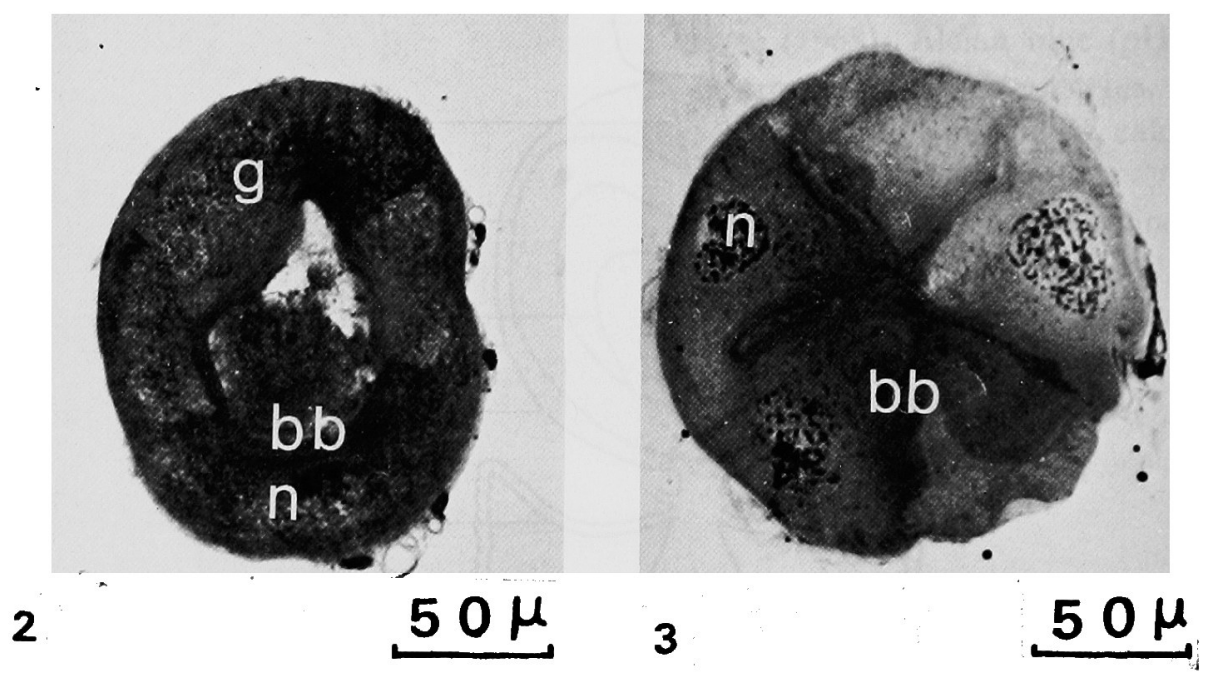

Figs. 2-3. 2, transverse section of distal tubule. Light micrograph of araldite section. Toluidine blue stained. Note the birefringent granules $(\mathrm{g})$ in the ground cytoplasm and in the lumen. The nucleus (n) is vaguely visible. The apical brush border (bb) is prominent. 3, transverse section of proximal tubule. Light micrograph of araldite section. Toluidine blue stained. Note the large nucleus (n) in each epithelial cell. The brush border (bb) is clear, and the lumen is narrow.

\section{Ultrastructure}

The apical microvilli are $4 \mu$ tall. The ground cytoplasm has abundant mitochondria, multivesicular bodies and lysosome-like bodies (Figs. 5, 12). The cell junction at the apical surface is a tight desmosome (Fig. 12).

The basal membrane is of the fibrillar type and is $0.8 \mu$ thick (Figs. 5, 13). Extensive basal infoldings are found, extending half distance towards the apical surface (Fig. 5). These infoldings have abundant mitochondria associated with them (Figs. 5, 13).

\section{Cytochemistry}

Test for alkaline phosphatase shows that the reaction products are associated with the brush border. The ground cytoplasm and basal cytoplasm yield strongly 


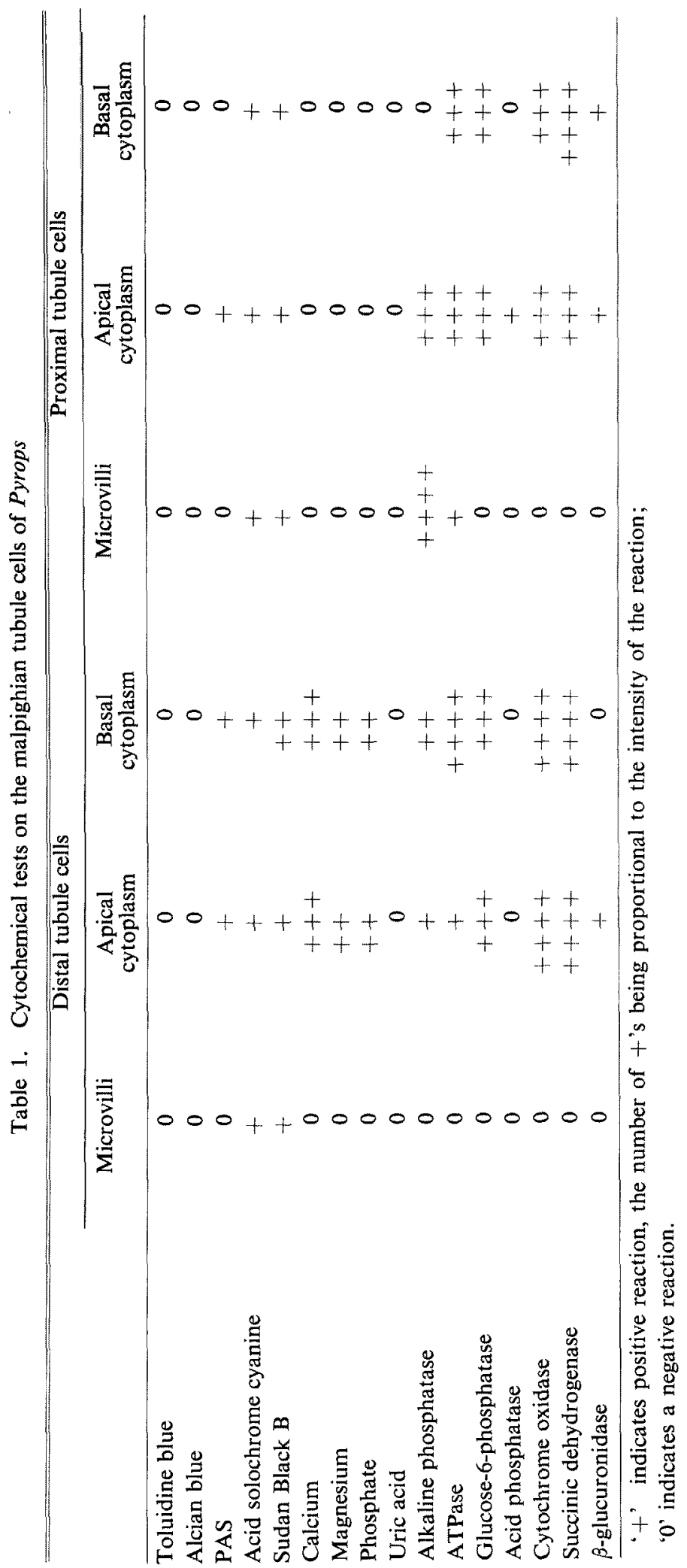




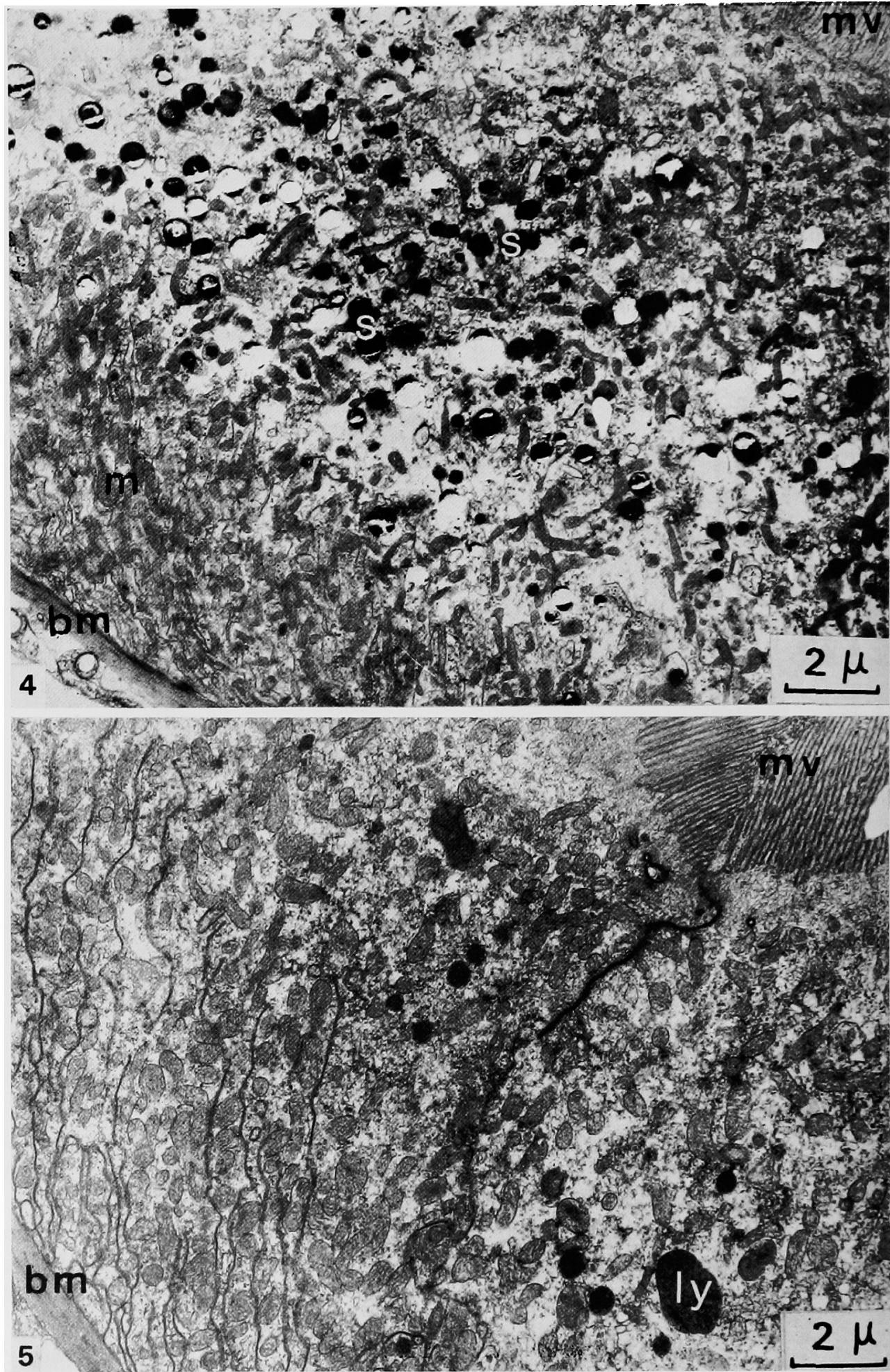

Figs. 4-5. 4, longitudinal section of distal tubule cell, showing apical microvilli (mv), mitochondria $(\mathrm{m})$, mineral spherites (s), and basement membrane (bm). 5, longitudinal section of proximal tubule cell, showing apical microvilli (mv), mitochondria (m), lysosome-like bodies (ly), and basement membrane (bm). 


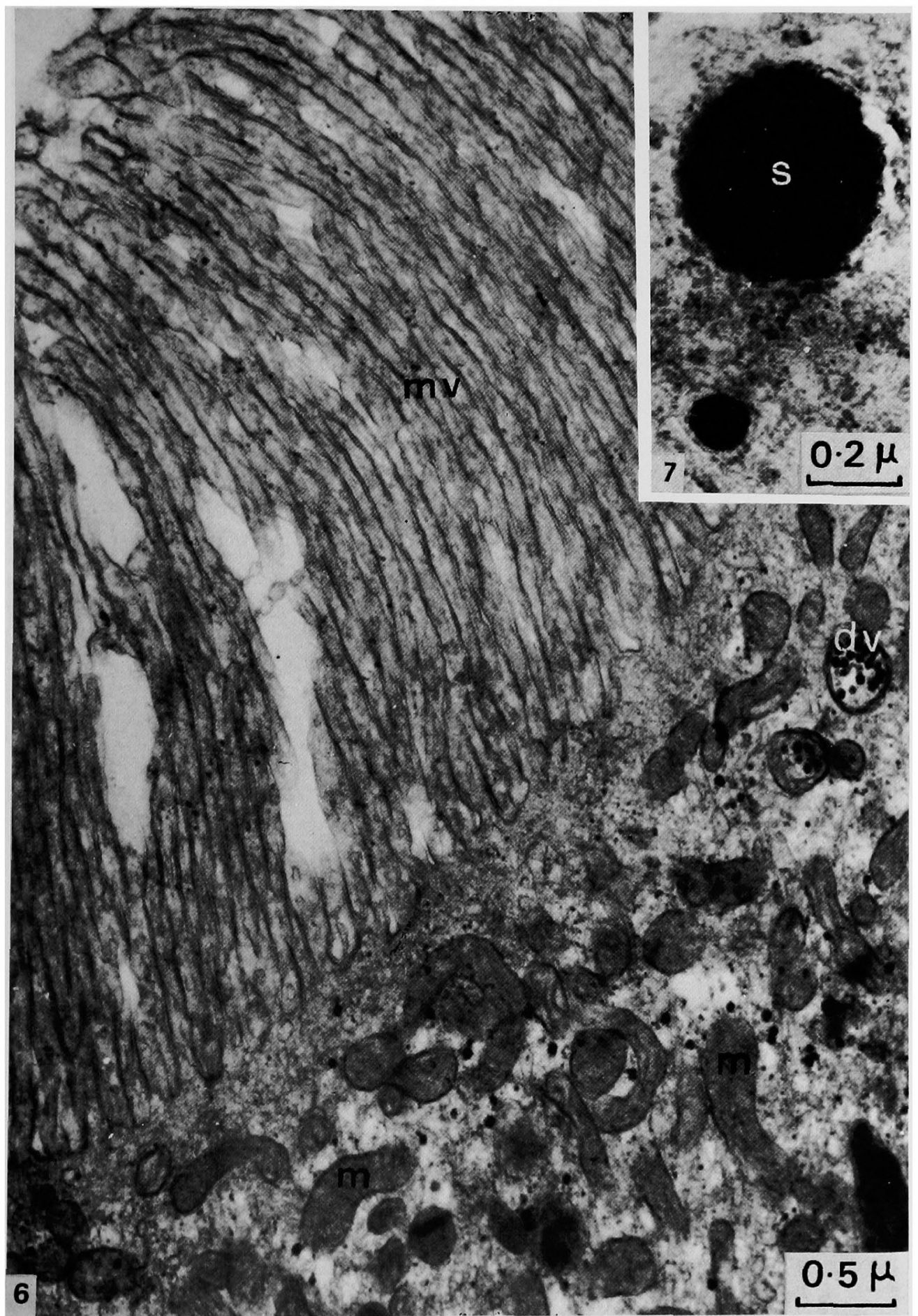

Figs. 6-7. 6, longitudinal section of apical region of distal tubule cell, showing microvilli (mv), mitochondria $(\mathrm{m})$, and electron dense vesicles $(\mathrm{dv})$. 7, high magnification of a mineral spherite (s). 

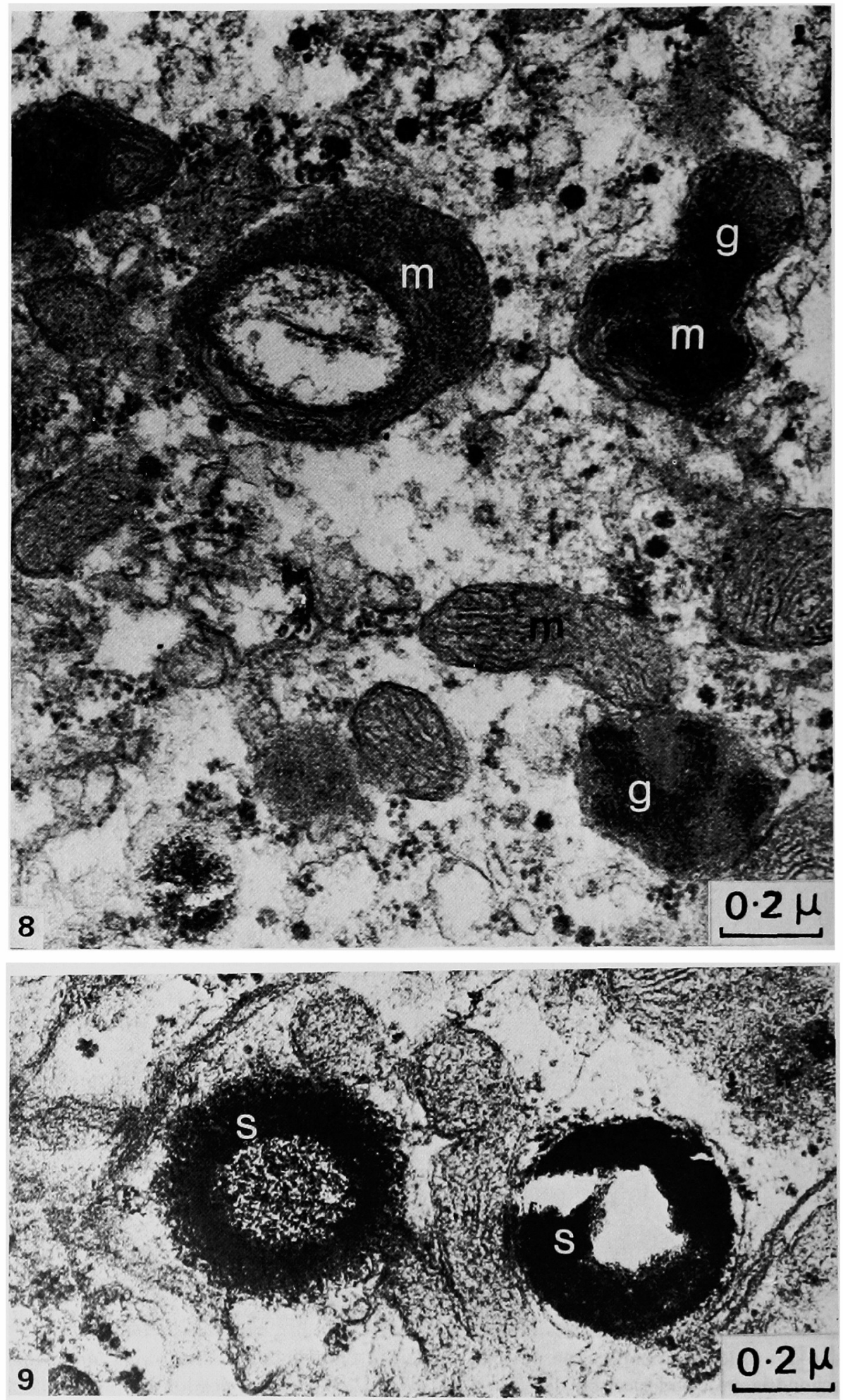

Figs. 8-9. 8, high magnification of mitochondria $(\mathrm{m})$ undergoing various degrees of mineralization to form spherites. Note dark granular deposits $(\mathrm{g})$ in the mitochondria. 9, mineral spherites showing various degrees of electron opacity. The middle part of a spherite may drop off during sectioning. 


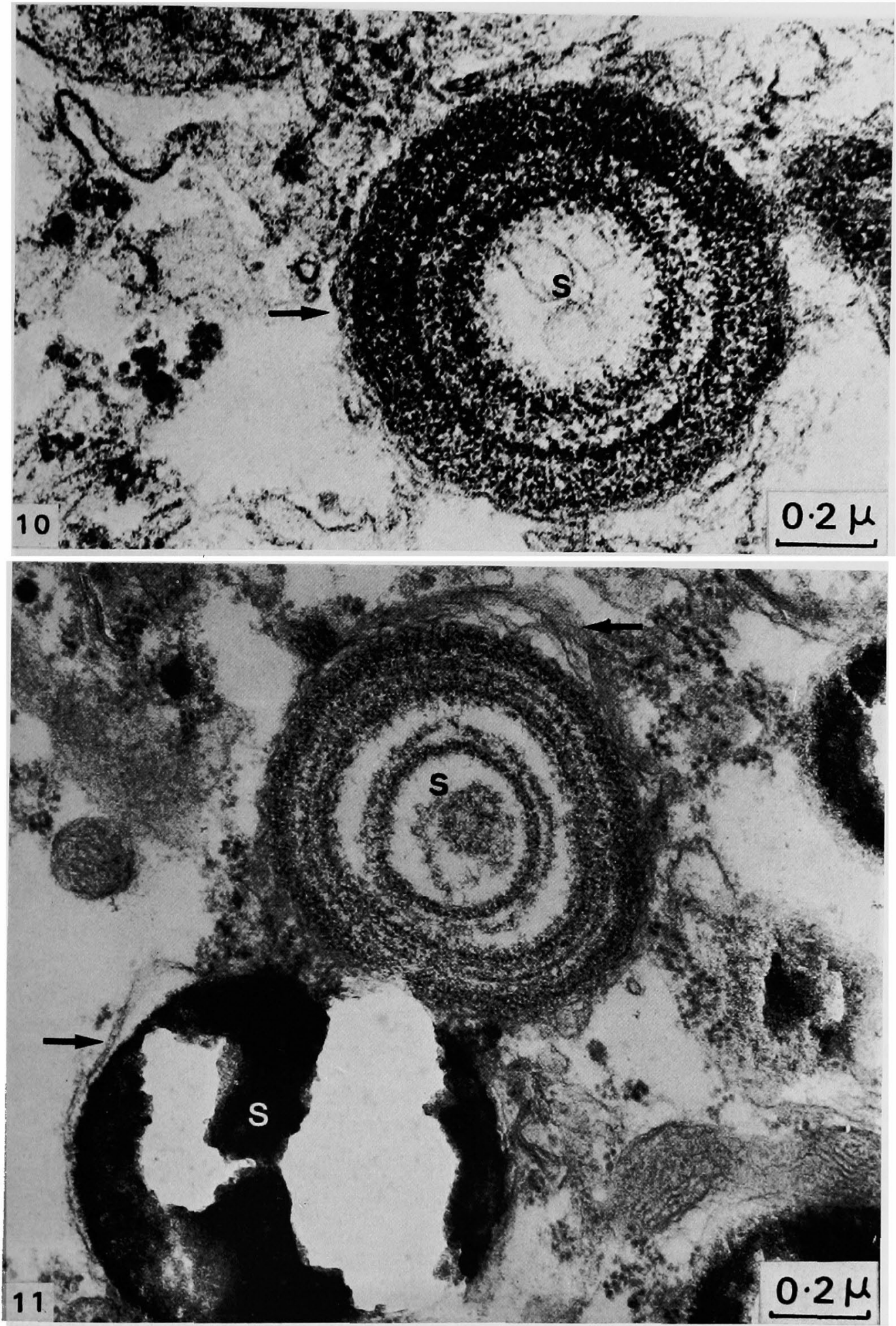

Figs. 10-11. As above, showing mineral spherite (s) with concentric layers of electron opacity. Arrows point to membranes associated with spherite formation. 

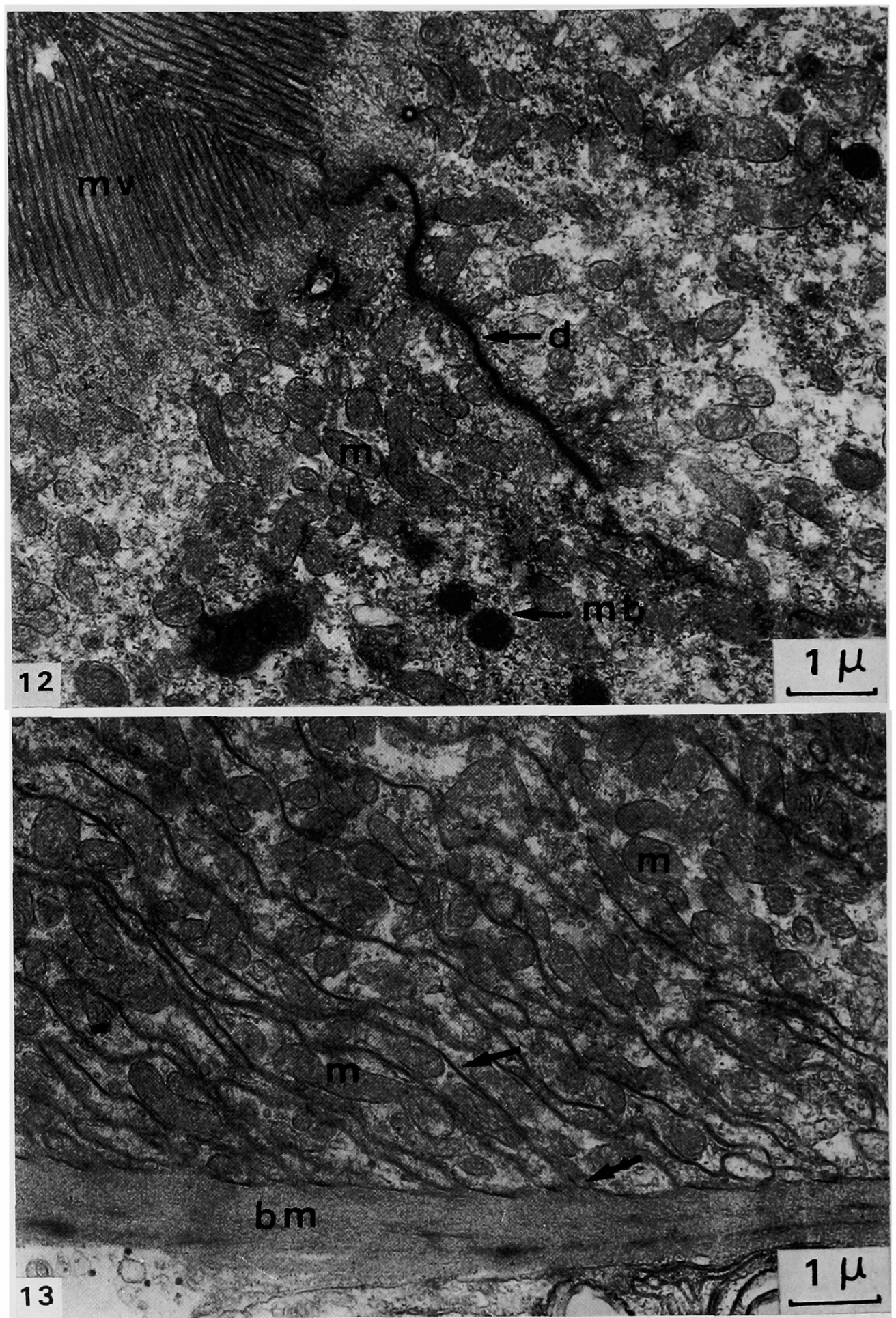

Figs. 12-13. 12, longitudinal section of apical region of proximal tubule cell, showing microvilli $(\mathrm{mv})$, desmosome (d), mitochondria $(\mathrm{m})$ and multivesicular bodies $(\mathrm{mb}) . \quad 13$, longitudinal section of basal region of proximal tubule cell, showing fibrillar type of basement membrane (bm), extensive basal infoldings (shown by arrows), and mitochondria (m). 
positive results for tests of ATPase, glucose-6-phosphatase, cytochrome oxidase and succinic dehydrogenase.

A weak positive result has been obtained for $\beta$-glucuronidase.

The proximal tubule cells give negative results for tests of calcium, magnesium, phosphates and uric acid.

Table 1 summarises the cytochemical properties of the proximal tubule cells.

\section{Discussion}

The insect excretory system is a combined action of the malpighian tubules and the rectum. The tubules secrete fluid into the rectum where certain useful materials are reabsorbed and are then transported back into the haemolymph (reviewed by Phillips 1970, Maddrell 1971, Wigglesworth 1972).

Functional differentiation of the malpighian tubules occurs in many insects whereby the malpighian tubule fluid is modified in chemical composition before draining into the hindgut, for example, in Rhodnius (Wigglesworth 1931, Wigglesworth and Salpeter 1962), in Calpodes (Irvine 1969), in Periplaneta (Wall et al. 1975) and in Drosophila (Wessing and Eichelberg 1969). Water conservation is thus successfully achieved.

Pyrops feeds on cambium sap. The latter has a relatively high concentration of mineral content. The Pyrops malpighian tubules are structurally and cytochemically differentiated to handle the cambium sap. It is suggested that these differentiation may be related to functions such as ion secretion, mineral storage and resorption of useful materials.

The distal tubule cells have numerous basal infoldings, forming long narrow intracellular channels extending deep into the cells. Many mitochondria are associated with these channels. The presence of enzymes such as ATPase, cytochrome oxidase and succinic dehydrogenase, which are related to transport and metabolism, indicate that secretion of ions could occur here.

Experimentally, Pyrops malpighian tubules have been shown to be able to excrete $0.1 \%$ amaranth injected into the haemocoel (Cheung, unpublished data). Thus the distal tubule cells secrete fluid as those in Rhodnius (Wigglesworth 1931, Wigglesworth and Salpeter 1962), in Dysdercus (Berridge 1965) and many other insects. Besides, the urine has a high concentration of potassium, sodium, chloride and phosphate (Marshall and Cheung 1975).

The distal tubule cells are also capable of mineral storage excretion. The spherites shown in light and electron micrographs stain positively with tests for calcium, magnesium and phosphate. These mineral spherites do not contain uric acid, and are comparable to those in the distal tubules in Rhodnius (Wigglesworth and Salpeter 1962).

Little is known about the mode of origin of the spherites in insect cells. According to authors such as Wigglesworth and Salpeter (1962), Cheung and Marshall (1973a), and Sohal et al. (1976), spherites can arise by many ways. Some of these are as follows:

Firstly, mineral spherites may possibly arise by the mineralization of mito- 
chondria (Wigglesworth and Salpeter 1962).

Secondly, mineral spherites may originate in cisternae formed from smooth parts of the endoplasmic reticulum (Cheung and Marshall 1973a). Areas of smooth endoplasmic reticulum are frequently expanded into wide cisternae, and it is within these that electron dense material appears to be laid down. The endoplasmic reticulum is often in whorls, which is reflected by the appearance, in young cells, of spherites arranged in concentric circles. The concentric circles have varying degrees of electron opacity.

Thirdly, dense materials may accumulate in multivesicular bodies or secondary lysosomes, and eventually result in mineral spherites (Sohal et al. 1976).

In Pyrops distal tubules, it appears that most of the spherites arise by the mineralization of mitochondria, although other methods mentioned above cannot be excluded. Further studies on these spherites are necessary in order to understand their exact modes of formations.

The Pyrops spherites in the distal tubules could be storage excretory products, comparable to those in Rhodnius (Wigglesworth and Salpeter 1962). Although the malpighian tubule fluid of Pyrops has not been analysed, the urine has high levels of potassium, sodium, chloride and phosphate (Marshall and Cheung 1975). Thus the distal tubule cells are chiefly responsible for excreting the excess minerals taken into the insect body by way of its food. A difference between Pyrops distal tubule and Rhodnius distal tubule, however, is that there are no mitochondria found in the apical microvilli of Pyrops.

The proximal tubule cells of Pyrops also have numerous basal infoldings, with many mitochondria associated with them. Transporting and metabolic enzymes such as ATPase, glucose-6-phosphatase, cytochrome oxidase, and succinic dehydrogenase are found in the ground cytoplasm. Alkaline phosphatase, however, has been localised at the apical brush border.

It may be conjectured that the fine structure and cytochemical properties of the proximal tubule cells suggest some sort of resorption of solutes occur here. The proximal tubules, together with the rectum, which possesses rectal glands (Cheung 1979), ensure that all useful materials are reabsorbed back into the haemolymph.

\section{Acknowledgements}

Part of this work was carried out at the Zoology Department of the University of Singapore. I am indebted to Mr. C. H. Cheong (University of Singapore) and Mr. Henry Shea (Chinese University of Hong Kong) for technical assistance. Thanks are also due to Mrs. Amy Shea for typing the manuscript.

\section{References}

Barka, T. and Anderson, P. J. 1963. Histochemistry: Theory, Practice and Bibliography. Harper and Row, New York.

Berridge, M. J. 1965. The physiology of excretion in the cotton stainer, Dysdercus fasciatus Signoret I. Anatomy, water excretion and osmoregulation. J. Exp. Biol. 43: 511-521. Cheung, W. W. K. 1979. An electron microscopic observation of the rectum of the lantern bug, 
Pyrops candelaria Linn. (Homoptera: Fulgoridae). J. Chinese Univ., Hongkong 5: 521-533.

- and Marshall, A. T. 1973a. Studies on water and ion transport in homopteran insects: ultrastructure and cytochemistry of the cicadoid and cercopoid midgut. Tissue and Cell $\mathbf{5}$ : 651-669.

-1973b. Water and ion regulation in cicadas in relation to xylem feeding. J. Insect Physiol. 19: $1801-1816$.

Culling, C. F. A. 1963. Handbook of Histopathological Techniques. 2nd ed. Butterworths, London.

Fredricsson, B. 1952. A modification of the histochemical method for demonstration of alkaline phosphatase in which the diffusion phenomenon is reduced. Experientia 8: 139.

Goodchild, A. J. P. 1963. Some new observations on the internal structures concerned with water disposal in sap-sucking Hemiptera. Trans. Roy. Entomol. Soc. Lond. 115: 217-237.

- 1966. Evolution of the alimentary canal in the Hemiptera. Biol. Rev. 41:97-140.

Irvine, H. B. 1969. Sodium and potassium secretion by isolated insect malpighian tubules. Amer. J. Physiol. 217: 1520-1527.

Jarial, M. S. and Scudder, G. G. E. 1970. The morphology and ultrastructure of the malpighian tubules and hindgut in Cenocorxa bifida Hung. (Hemiptera: Corixidae). Z. Morph. 68: 269-299.

Kershaw, J. C. W. 1910. A memoir on the anatomy and life history of the homopterous insect Pyrops candelaria. Zool. Jb. (Syst.) 29: 105-124.

Marshall, A. T. 1965. Spittle-production and tube-building by cercopid nymphs (Homoptera) 3. The cytology and function of the fibril zone of the malpighian tubules of tube-building nymphs. Quart. J. Microsc. Sci. 106: 37-44.

-1966. Histochemical studies on a mucocomplex in the malpighian tubules of cercopid larvae. J. Insect Physiol. 12: 925-932.

- 1968. The chemical nature of malpighian tubule mucofibrils in cercopoid dwelling-tubes. J. Insect Physiol. 14: 1435-1444.

- and Cheung, W. W. K. 1970. Ultrastructure and cytochemistry of an extensive plexiform surface coat on the midgut cells of a fulgorid insect. J. Ultrastruct. Res. 33: 161-172.

- 1973. Calcification in insects: the dwelling-tube and midgut of machaerotid larvae (Homoptera). J. Insect Physiol. 19: 963-972.

- 1974. Studies on water and ion transport in homopteran insects: ultrastructure and cytochemistry of the cicadoid and cercopoid malpighian tubules and filter chamber. Tissue and Cell 6: 153-171.

- 1975. Ionic balance of Homoptera in relation to feeding site and plant sap composition. Ent. Exp. and Appl. 18: 117-120.

Pearse, A. G. E. 1968. Histochemistry: Theoretical and Applied. 3rd ed. Churchill, London.

Phillips, J. E. 1970. Apparent transport of water by insect excretory systems. Amer. Zoologist 10: 413-436.

Rutenburg, A. M., Goldberg, J. A., Rutenburg, S. H. and Laing, R. I. 1960. The histochemical demonstration of $\alpha$-D-glucosidase in mammalian tissues. J. Histochem. Cytochem. 8: $268-272$.

Seligman, A. M., Tsou, K. C., Rutenburg, S. H. and Cohen, R. B. 1954. Histochemical demonration of $\beta$-D-glucuronidase with a synthetic substrate. J. Histochem. Cytochem. 2: 209_ 229.

Sohal, R. S., Peters, P. D. and Hall, T. A. 1976. Fine structure and X-ray microanalysis of mineralized concretions in the malpighian tubules of the house fly, Musca domestica. Tissue and Cell $8: 447-458$.

Steward, F. C. and Sutcliffe, J. F. 1959. Plant Physiology. A Treatise. Academic Press, New York and London.

Wachstein, M. and Meisel, E. 1956. On the histochemical demonstration of glucose-6-phosphatase. J. Histochem. Cytochem. 4: 592.

- 1957. Histochemistry of hepatic phosphatase at a physiological pH with special reference to 
the demonstration of bile canaliculi. Amer. J. Clin. Pathol. 27: 13-23.

Wall, B. J., Oschman, J. L. and Schmidt, B. A. 1975. Morphology and function of malpighian tubules and associated structures in the cockroach, Periplaneta americana. J. Morph. 146: $265-306$.

Wessing, A. and Eichelberg, D. 1969. Elektronenoptische Untersuchungen an den Nierentubuli (Malpighische Gefässe) von Drosophila melanogaster I. Regionale Gliederung der Tubuli. Z. Zellforsch. mikrosk. Anat. 101: 185-322.

Wigglesworth, V. B. 1931. The physiology of excretion in a blood-sucking insects, Rhodnius prolixus (Hemiptera, Reduviidae) II. Anatomy and histology of the excretory system. J. Exp. Biol. 8: $428-442$.

- 1972. The Principles of Insect Physiology. 7th ed. Chapman and Hall, London.

- and Salpeter, M. M. 1962. Histology of the malpighian tubules of Rhodnius prolixus Stal (Hemiptera). J. Insect Physiol. 8: 299-307. 